\title{
Parallel evaluation of cell-based phage display panning strategies: Optimized selection and depletion steps result in AML blast-binding consensus antibodies
}

\author{
THERESA WEBER $^{1,4}$, SIBYLLE PSCHERER ${ }^{1}$, ULRIKE GAMERDINGER ${ }^{1}$, \\ ANDREA TEIGLER-SCHLEGEL ${ }^{1}$, NATALJA RUTZ ${ }^{1}$, WOLFGANG BLAU ${ }^{2}$, \\ MATHIAS RUMMEL $^{3}$, STEFAN GATTENLÖHNER ${ }^{1}$ and MEHMET KEMAL TUR ${ }^{1}$
}

\footnotetext{
${ }^{1}$ Institute of Pathology, Justus Liebig University Giessen, University Hospital Giessen and Marburg, D-35392 Giessen;

${ }^{2}$ Department for Hematology, Oncology and Palliative Care, Helios Dr Horst Schmidt Kliniken, D-65199 Wiesbaden;

${ }^{3}$ Department for Hematology, Justus Liebig University Giessen, University Hospital Giessen and Marburg,

D-35392 Giessen, Germany
}

Received May 27, 2021; Accepted August 3, 2021

DOI: $10.3892 / \mathrm{mmr} .2021 .12407$

\begin{abstract}
Phage display technology (PD) is a powerful technique for the generation of tumor-targeting antibodies. However, there are a number of different selection methods established in different laboratories around the world. Cell-based PD panning methods using primary tumor cells are particularly heterogeneous between laboratories, which can lead to inconsistent results. Therefore, the present study evaluated different cell-based PD selection methods regarding their potential to generate acute myeloid leukemia (AML) blast-binding antibodies. In addition to this evaluation, the present study improved the PD procedure by optimizing selection as well as depletion strategies. To the best of our knowledge, the current
\end{abstract}

Correspondence to: Dr Mehmet Kemal Tur, Institute of Pathology, Justus Liebig University Giessen, University Hospital Giessen and Marburg, Langhansstrasse 10, D-35392 Giessen, Germany

E-mail:mehmet.k.tur@patho.med.uni-giessen.de

Present address: ${ }^{4}$ Department for Hematology, Oncology and Immunology, Philipps University Marburg, University Hospital Giessen and Marburg, D-35033 Marburg, Germany

Abbreviations: AD, antigen diversity; anti-M13, antibody against
phage proteins; DGC, density gradient centrifugation; DS, depletion
step; LE, lysis of erythrocytes; MA, enrichment of monocytes by
adherence; NT, supernatant of non-transfected 293T cells; PD,
phage display; PS, panning step; RPMI, RPMI 1640 GlutaMAX
medium; RT, room temperature; scFv, single chain fragment
variable; scFv-Fc, scFv cloned to a fragment crystallizable of an
IgG2a mouse antibody; SR, selection round; WB-FACS, washing
buffer for fluorescence-activated cell-sorting experiments

Key words: acute myeloid leukemia, phage display technology, depletion antigen diversity, enrichment of blasts, consensus phage, internalizing antibody study demonstrated for the first time that antigen diversity during the depletion step is of importance for the enrichment of tumor-targeting phage antibodies. It is demonstrated that medium levels of depletion antigen diversity led to the most promising antibody candidates. In addition, it was determined that purification of blast cells from patients with AML by immunomagnetic separation ameliorated the selection of AML-binding phages during panning. Furthermore, suggesting a common design-related mechanism using a 'single-pot' PD library, such as the well-known Tomlinson single-chain fragment variable ( $\mathrm{scFv}$ ) library, the present study identified specific binding consensus phage particles in independent panning procedures. By means of these optimized strategies, four promising AML blast-binding phage particles were isolated and soluble scFv-Fc (scFv cloned to a fragment crystallizable of an $\mathrm{IgG} 2$ a mouse antibody) fusion proteins were produced. These scFv-Fc antibodies bound the surface of AML blasts and were successfully internalized into their cytoplasm, indicating that they are potential immunoconjugate candidates for AML immunotherapy.

\section{Introduction}

Acute myeloid leukemia (AML) is a heterogeneous disease characterized by clonal expansion of myeloid progenitors, called blasts (1). Its median survival time without treatment is 17 weeks (2) and its median age at diagnosis is 69 years (3). The incidence is reported as 4 cases per 100,000 population (4).

Although there is rapidly increasing knowledge about the pathogenesis of AML, particularly regarding the role of genetics (5-7), the treatment of AML has not changed fundamentally in the last four decades (1) and the ' $7+3$ ' chemotherapy regimen is still the standard of care (4).

Targeted therapies, such as midostaurin, a multikinase inhibitor (8), or enasidenib, an IDH2-inhibitor (9), are slow to be established in the clinical setting and are only approved for a small cohort of patients so far (9). 
Molecular therapies have also failed to prove themselves as universal remedy until now (10), so other ways of dealing with this life-threatening disease are the subject of intensive research. Among these, therapeutic antibodies which attack malignant cells, e.g., gemtuzumab ozogamicin, a CD33 immunotoxin conjugate (11), are particularly promising candidates for the effective treatment of AML.

Phage display is an effective technique for the development of novel antibodies $(12,13)$. This in vitro method uses the genotype to phenotype linkage of bacteriophages to express different types of recombinant antibodies on the surface of phage particles (14). Antibody fragments are selected during several rounds of panning by their affinity to a given, not necessarily known, but relevant antigen, such as the surface of intact cells, cell lysates, fixed tissues or membrane fractions (15-19). Furthermore, in vitro selection techniques allow optimizing the biopanning conditions, such as modifying the negative (depletion) and positive (selection) steps to facilitate the isolation of antibodies with desired binding properties. However, selection and depletion conditions vary tremendously between different laboratories regarding e.g., applied biopanning protocols, phage antibody libraries, and target antigens.

Particularly the depletion step (DS), i.e., the absorption of non-specific antibody phage particles to minimize false-positive rates and, therefore, to exclude cross-reactive antibodies, is performed very differently in different labs. While it has been determined that mononuclear cells (PBMCs) are widely established as depletion antigen fraction during whole-cell panning procedures (19-22), the efficiencies of PBMC-depleted libraries are often limited. Therefore, we hypothesized that using mononuclear cells, i.e., lymphocytes and monocytes only, for depletion is not sufficient to achieve efficient elimination of unspecific phage particles.

Moreover, we postulated that efficient elimination of unspecific phage particles during the whole-cell-biopanning process has major impact on the generation of target cell-specific antibodies. Therefore, we examined the correlation between depletion efficiency and depletion antigen diversity in different depletion approaches by adding or overrepresenting different specific cell fractions from healthy whole blood samples.

Our aim was to optimize and standardize the biopanning methodology to generate target- specific antibodies against primary AML blasts by comparing different panning procedures. For this, we adapted phage selection procedures in consideration of patient blast cell counts and found that quantity and quality of blast cells as well as depletion antigen diversity are critical for the selection outcome.

The result of this research will have significant implications on the design and optimization of library selection strategies using primary patient-derived tumor cells as target antigens.

\section{Materials and methods}

Literature research. A literature research was performed at https://www.ncbi.nlm.nih.gov/pubmed. After analyzing the query results, seven articles were selected which show the most important differences among different labs.

Cells of AML patients and healthy blood samples. All AML patients gave written informed consent, and the clinical ethics committee of the Justus Liebig University Giessen approved all experimental work (ref: 140/16). Healthy leukocyte samples were obtained from voluntary donors with blood groups A, $B$, and 0 . If necessary, those samples were stored using density gradient centrifugation (DGC) and cryoconservation (Freezing medium; Life Technologies; \#12648-010).

In addition, AB blood serum was received from voluntary donors after written informed consent as well. Approval of the clinical ethics committee of the Justus Liebig University Giessen was also obtained for this procedure (ref: 05/00).

\section{Cell culture and cell methods}

Kasumi-1 AML cell line. The human AML-M2-derived cell line Kasumi-1 was used as model cell line for e.g., testing of internalization behavior. The cell line was purchased from the German Resource Centre for Biological Material (DSMZ; ACC 220). Kasumi-1 cells were cultured in 80\% RPMI-1640 Gluta- MAX ${ }^{\mathrm{TM}}$ medium (RPMI; Life Technologies; \#61870-044) and supplemented with 20\% fetal bovine serum (FBS; Life Technologies; \#10270-106) at $37^{\circ} \mathrm{C}, 5 \% \mathrm{CO}_{2}$ (19).

2937 cell line and transfection. The embryonic kidney cell line 293T, purchased from the American Type Culture Collection (ATCC; CRL 3216), was cultured in 90\% RPMI containing $10 \%$ FBS and $1 \%$ penicillin-streptomycin mixture (Life Technologies; \#15140-122) (19).

The cell line was used for transfection by incubating $5 \times 10^{4}$ cells with $1 \mathrm{mg}$ pMS2-plasmid DNA bearing the scFv-Fc fusion protein $(\mathrm{scFv}-\mathrm{Fc})$ plus $3 \mu \mathrm{l}$ FuGene HD Transfection Reagent (Promega; \#E2311) at room temperature for $15 \mathrm{~min}$. Subsequently, 293T cells were subjected to a selection pressure by zeocin (Life Technologies; \#R25001, final concentration $100 \mu \mathrm{g} / \mathrm{ml}$ ) to yield higher amounts of transfected cells producing scFv-Fc and secreting them into the supernatant. The final duration of the incubation with zeocin selection pressure was three weeks at $37^{\circ} \mathrm{C}, 5 \% \mathrm{CO}_{2}$. Transfection efficiency was confirmed by flow cytometry through an enhanced green fluorescence protein (eGFP) produced as reporter protein by those cells secreting the scFv-Fc.

Antibody library and vectors. The well-known human scFv antibody library Tomlinson J (Medical Research Council Laboratory) was used for the selection process. This library is based on a single human framework (VH-3 and $\mathrm{V}_{\kappa}-1$ ) and a chain diversity of NNK triplets which is incorporated in the complementarity determining regions 2 and 3 (CDR2/3) (23). The library was constructed by the pIT2-phagemid vector and stored in the E. coli strain TG1 until usage.

After the selection procedure, scFvs were converted from the pIT2 to the pMS2 vector to receive a bivalent, recombinant and homodimerized scFv-Fc antibody that included the Fc-fragment of a mouse-IgG2a-antibody.

Phage display $(P D)$. Phage production and rescue was carried out as previously described (19): The Tomlinson J antibody library was infected with M13K07DpIII hyperphage (Progen Biotechnik GmbH; \#PRHYPE-XS) and M13K07 helper phage (New England Biolabs; \#N0315S). While M13K07DpIII was used during the first of three selection rounds (SR) only, M13K07 was employed during the second and third SR. 
Subtractive selection including optimized depletion steps were performed with different healthy blood cell subsets prior to positive selection on AML blasts to remove common and non-specific antibody binders. An overview of the different cell-based phage panning strategies applied is shown in Fig. 1.

Negative selection: Depletion step (DS). For efficient elimination of unspecific phage particles during cell-panning, blood samples from healthy donors were collected to isolate different blood cell fractions for depletion. Samples were anti-coagulated with either heparin (used in density gradient centrifugation and enrichment of monocytes) or EDTA (ethylenediamine tetra-acetic acid, used in lysis of erythrocytes). Panning started with three depletion steps for the phage library on centrifuged or lysed blood samples. Cell counts required for the DS (i.e., cells from a healthy donor) and the panning step (i.e., blasts from an AML patient) were adjusted to $10 \times 10^{6}$ cells per sample. However, monocytes were adjusted to $2.5 \times 10^{6}$ cells per sample.

Density gradient centrifugation was performed for patients 0 and A. Lysis of erythrocytes was carried out for patients B, C and D (Fig. 1). By contrast, enrichment of monocytes was performed for patient D only as second DS.

Density gradient centrifugation (DGC). Peripheral blood was mixed in a ratio of 1:1 with RPMI. Subsequently, one third Lymphoprep $^{\mathrm{TM}}$ (Axis-Shield; \#1114544) medium was overlaid with two thirds of the RPMI-blood-mixture and centrifuged at $1,800 \mathrm{rpm}$ for $30 \mathrm{~min}$. Afterwards, separated peripheral blood mononuclear cells (PBMC) were washed twice with RPMI, centrifuged at $10 \mathrm{~min}$ and either used directly or stored at $-80^{\circ} \mathrm{C}$ as reviewed above.

Lysis of erythrocytes (LE). The commercially available lysis solution (BD Pharm Lyse ${ }^{\mathrm{TM}}$; Becton-Dickinson (BD); \#555899) was mixed in a ratio of 1:10 with purified water $(\mathrm{pH} 7.3) .25 \mathrm{ml}$ reagent was added to $2.5 \mathrm{ml}$ blood sample, then shaken for $12 \mathrm{~min}$ and subsequently centrifuged at $1,200 \mathrm{rpm}$ for $5 \mathrm{~min}$. The pellet was resuspended with $25 \mathrm{ml}$ PBS (phosphate buffered saline, $\mathrm{pH}=7.4$ ) plus $1 \%$ FBS and centrifuged again at $1,200 \mathrm{rpm}$ for $5 \mathrm{~min}$.

Enrichment of monocytes via adherence (MA). After DGC, the obtained PBMCs were seeded in T175 $\mathrm{cm}^{2}$ culture flasks, resuspended in RPMI supplemented with $10 \%$ FBS at a density of $2-3 \times 10^{6}$ cells $/ \mathrm{ml}$. Incubation was performed at $37^{\circ} \mathrm{C}$ for $1 \mathrm{~h}$. Subsequently, the adherent monocytes were cleaned from remaining supernatant by washing twice with preheated PBS $\left(37^{\circ} \mathrm{C}\right)$. RPMI plus $10 \%$ FBS was added and incubated at $37^{\circ} \mathrm{C}$ overnight.

Positive selection: Panning step (PS). Target cell concentration is essential in cell-based phage display. Therefore, at least one round of CD34 magnetic activated cell sorting (MACS) was performed to concentrate patients' targeted blast cells if the blast percentage was below $90 \%$ after DGC. Thus, samples from patient $\mathrm{A}$ and $\mathrm{B}$ were sorted for all three SR, patient $\mathrm{C}$ samples were sorted for the first SR only (Fig. 1) and material from patient $\mathrm{D}$, which contained a blast percentage above $90 \%$,

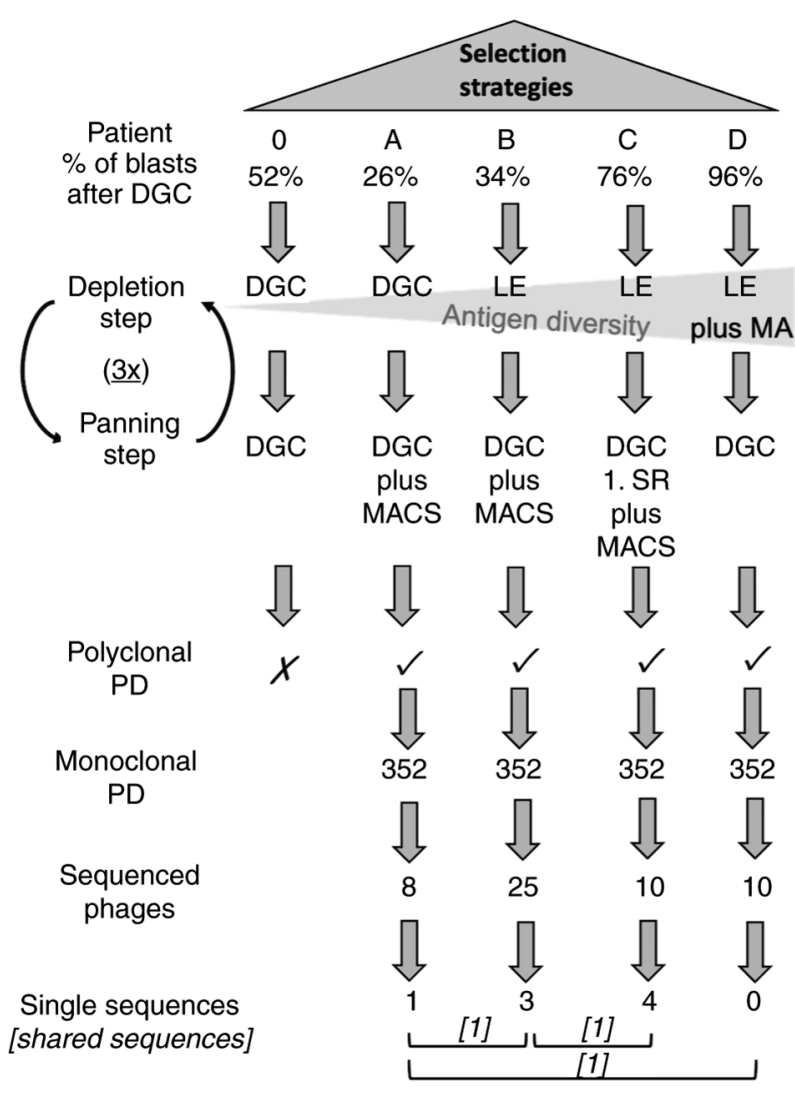

Figure 1. Selection strategies performed. All five patients (0, A, B, C and D) were included. The depletion steps and planning steps are depicted. In subsequent polyclonal PD FACS analysis patient 0 failed to show any enrichment. Hence, only the selection strategies of patient A, B, C and D reached monoclonal analysis where the most promising phages of each selection strategy were chosen and sequenced. After sequencing, one unique sequence was revealed in the sequenced phages of patient $\mathrm{A}$, three unique sequences within patient $\mathrm{B}$ and four single sequences in patient $C$. Furthermore, three shared sequences were revealed among the selection strategies (named consensus phages) which are symbolized with square brackets. Cross indicates not continued. Tick indicates continued. 3x, three times; DGC, density gradient centrifugation; LE, lysis of erythrocytes; MA, adherence of monocytes; MACS, magnetic-activated cell sorting; PD, phage display; SR, selection round.

was not sorted. Samples from patient 0 served as control and were therefore not CD34-sorted at all.

Enrichment of peripheral blood CD34 ${ }^{+}$cells. Blood cells from patient samples were enriched for CD34-positive blasts by using immunomagnetic beads according to the manufacturer's protocol (CD34 MicroBeads Kit; Miltenyi Biotec; \#130-046-702). Purity was controlled using flow cytometry (FACS) against the precursor antigen CD34 (CD34-antibody conjugated with fluorescein-isothiocyanate (CD34-Fitc), Lot B213405, monoclonal, mouse anti-human; Biolegend) (24). CD34-positive blasts were used for cell-panning directly after sorting. If the initial blast cell count after DGC was below 75\%, all three selection rounds were conducted on CD34-enriched material. If cell counts were above $90 \%$, no CD34 enrichment was performed. Cells were only purified for the first SR if blast counts were between 75 and $90 \%$.

Flow cytometry-based analysis of polyclonal phage antibody binding. Polyclonal FACS analysis was performed to determine the AML blast-specific enrichment of antibody phages 
obtained after three rounds of subtractive cell-panning (Fig. 2). Phage rescue was performed as described above:

In brief, for each individual stain, $3 \times 10^{5}$ patient cells after DGC were used and blocked for $11 / 2 \mathrm{~h}$ in $2 \%$ MPBS (milk powder plus PBS) at room temperature. In addition, each polyclonal phage solution was diluted with MPBS to achieve a titer of $5 \times 10^{9}$ colony forming units $(\mathrm{CFU}) / \mathrm{ml}$ and was blocked for $2 \mathrm{~h}$ on a rotary instrument. Subsequently, $100 \mu \mathrm{l}$ phage solution was added to the patient's cells and incubated $1 \mathrm{~h}$ at $4^{\circ} \mathrm{C}$. After washing with washing buffer for FACS experiments (WB-FACS, i.e. PBS containing 0.2\% BSA; Sigma-Aldrich, Merck KGaA; \#A7906-100G, 0.1\% $\mathrm{NaN}_{3}$ ) and centrifugation at 2,600 rpm for $5 \mathrm{~min}$ at room temperature (RT), staining with a secondary antibody directed against a phage protein (anti-M13, monoclonal, mouse anti-phage, diluted 1:10.000 in 2\% MPBS; GE Healthcare; \#27942001) was conducted.

After incubation for $30 \mathrm{~min}$ at $4^{\circ} \mathrm{C}$ and centrifugation at 2,600 rpm for $5 \mathrm{~min}$ at RT, a third antibody conjugated with a fluorochrome was added (i.e. a goat anti-mouse antibody labelled with fluorescein-isothiocyanate, polyclonal, Lot 6287542; BD Biosciences; dilution 1:50). The staining procedure of the third antibody was performed in the same manner as the secondary antibody stain.

Finally, antibody binding was measured using the Guava easycyte 5HT flow cytometer (Merck Millipore). All FACS data were analyzed by InCyte 2.7 (Merck Millipore).

Isotype controls were used for setting up the instrument (Isotype Fitc, Lot B213387, monoclonal, mouse anti-human, Biolegend), cells without bound phage antibody were used as negative control and Kas-1 phage antibody (against Kasumi-1, unpublished) served as internal positive control.

Binding activity was scored positive (+), if at least $10 \%$ of the cell population (25) were confirmed positive and if an increase in median fluorescence intensity of at least $75 \%$ was detectable compared to the fluorescence signal of the control (unselected, naïve Tomlinson J library).

Flow cytometry-based analysis of monoclonal phage antibody binding. The binding specificity of monoclonal phage antibodies was verified by monoclonal FACS analysis. For this purpose, randomly picked single bacterial colonies from the third SR of each FACS-positive polyclonal phage pool were analyzed.

A 96-well plate was filled with $180 \mu 1$ Yeast Extract Tryptone Difco ${ }^{\mathrm{TM}}$ Medium (BD; \#11738892) containing $100 \mu \mathrm{g} / \mathrm{ml}$ ampicillin and $1 \%$ glucose. Single bacterial colonies were diluted in this medium and incubated overnight at $37^{\circ} \mathrm{C}$ under agitation at $180 \mathrm{rpm} .2 \mu \mathrm{l}$ bacterial solution were transferred to another 96 -well plate filled with the same medium as described above and grown for $2 \mathrm{~h}$ at $37^{\circ} \mathrm{C}$ under agitation at $180 \mathrm{rpm}$.

Subsequently, $30 \mu \mathrm{l}$ of hyperphage solution (1:100 diluted in PBS) was added to each well, incubated at $37^{\circ} \mathrm{C}$ for $30 \mathrm{~min}$ without agitation, and $30 \mathrm{~min}$ with agitation. Subsequently, samples were centrifuged for $10 \mathrm{~min}$ at $4,000 \mathrm{rpm}, 4^{\circ} \mathrm{C}$. The supernatant was discarded and replaced by the same medium as described above plus $50 \mathrm{mg} / \mu 1 \mathrm{Kanamycin}$. Finally, samples were incubated overnight at $30^{\circ} \mathrm{C}, 180 \mathrm{rpm}$, to complete phage rescue.

For FACS analysis, $1 \times 10^{5}$ cells were added into each well of another 96-well plate. If blasts were tested, they were treated in the same manner by pure density gradient centrifugation. If healthy donors were tested, the cells were treated the same way as they were for the correspondent selection strategy.

All cells were blocked in 2\% MPBS for at least 1 1/2 h. Rescued phages were blocked for $2 \mathrm{~h}$ under the same conditions. After blocking, rescued phages were added to each cell-containing well and incubated at $4^{\circ} \mathrm{C}$ for $1 \mathrm{~h}$. The subsequent staining procedure was identical to the staining procedure used during polyclonal analysis except for the centrifugation settings, which were adjusted to $1,500 \mathrm{rpm}$, $5 \mathrm{~min}$. Promising phages were sequenced. Unique scFv clones were investigated thoroughly as single phage particles.

Flow cytometry-based analysis of phage binding by titration measurements. Single phages, i.e., phages not tested in a 96-well format which were therefore titratable, were normalized to a titer of $5 \times 10^{10} \mathrm{CFU} / \mathrm{ml}$ and phage rescue was performed as described above. AML cells underwent a DGC. In addition, cells of patient A and B were CD34-sorted before staining. Subsequently, the staining was carried out as described for polyclonal analysis. Moreover, cells of healthy donors were evaluated for cross-reactivity by the analyzed phages (Fig. 3).

First, these healthy cells were treated by lysis of erythrocytes. Second, cells were stained equally to the malignant cells. Third, single phage analysis was carried out using flow cytometry in the same way as described above and evaluated by the same criteria as the polyclonal PD.

Production and flow cytometry analysis of $s c F v-F c$ fusion proteins

Sanger sequencing and $s c F v-F c$ fusion protein production. Specific scFv clones were sequenced by sanger sequencing. All clones harboring an amber termination codon (TAG) in their sequence (see 3.4) underwent site-directed mutagenesis as previously described (26). A glutamine (Q) was inserted instead of the amber codon to enable eukaryotic expression (Table I). Primers were created by LasergeneCoreSuite 14 (DNASTAR Inc.) and ordered by Eurofins Genomics GmbH (Table II).

Then, all selected scFv were cloned in frame into SfiI-NotI restriction sites of the eukaryotic expression vector pMS2 to express a bivalent antibody scFv-Fc (23).

Subsequently, 293T cells were transfected with the insert-bearing pMS2 vector and transfected cells were selected under zeocin pressure as described above. Finally, scFv-Fc fusion proteins secreted into the supernatant of 293T were verified by western blot and FACS analysis.

Western blot analysis of $s c F v-F c$ fusion proteins. For western blot analysis, a sodium dodecyl sulphate polyacrylamide gel electrophoresis was conducted. Bolt ${ }^{\mathrm{TM}} 8 \%$ Bis-Tris plus gels (Thermo Fisher Scientific; \#NW00080BOX) were run with NuPAGE ${ }^{\circledR}$ MOPS SDS Running Buffer (20X) (Life Technologies; \#NP0001) at $200 \mathrm{~V}, 50 \mathrm{~min}$. The negative control was supernatant of non-transfected $293 \mathrm{~T}$ cells (NT). A scFv-Fc fusion protein previously confirmed in another experiment served as positive control. $\mathrm{ScFv}-\mathrm{Fc}$ fusion proteins were usually purified using Protein A/G UltraLink Resin (Thermo Fisher Scientific; \#53132) affinity chromatography. Then, purified scFv-Fc fusion proteins were quantified using the BCA assay (Thermo Fisher Scientific; \#23227), commonly 

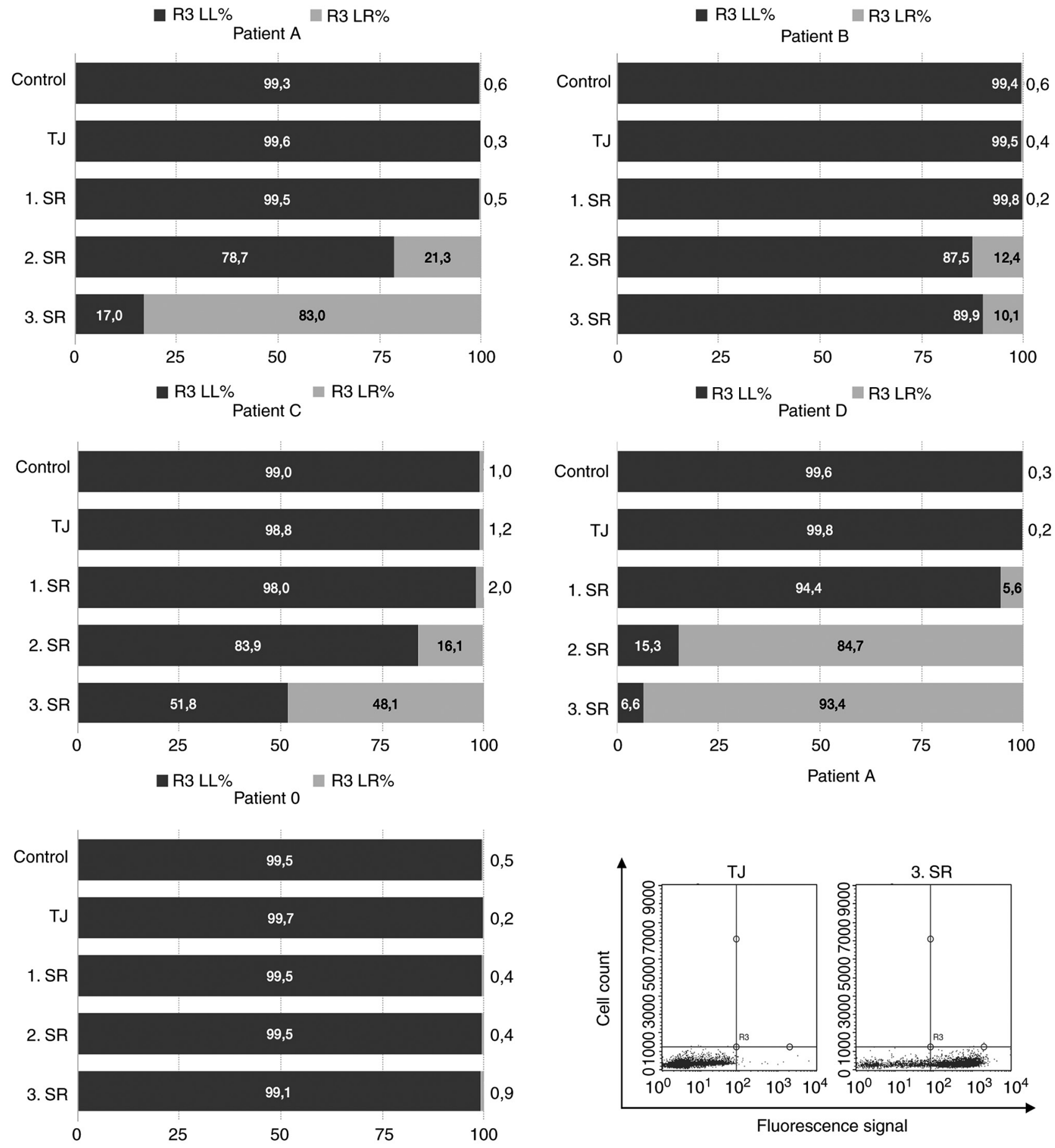

Figure 2. Binding analysis by flow cytometry. Bar graphs represent the results of the polyclonal binding of phage antibodies. These graphs resulted from FACS scatter plots plotting cell counts against fluorescence signals. Shifts regarding successful enrichment of phages are delineated by an increase in size of the light grey bars. In descending order, the experimental control, the unselected TJ library and the output of SRs 1 to 3 (1-3. SR) of each individual patient are shown. No polyclonal enrichment was seen for patient 0 (indicated by no change in the dark grey bars). Flow cytometric plot equivalent of patient A is shown in the lower right-hand corner. A shift from the LL quadrant (\%) towards the LR (\%) of the overall gate called R3 corresponded to the shift of the bar graphs. TJ, Tomlinson J library; SR, selection round; LL, lower left; LR, lower right.

revealing concentrations in the range of $0.15-0.25 \mathrm{mg} / \mathrm{ml}(23)$ Spectra Multicolor Broad Range Protein Ladder (Thermo Fisher Scientific; \#26634) was added as marker of molecular weight. For each lane $20 \mu \mathrm{l}$ sample volumes mixed with equivalent volumes of sample loading buffer (NuPAGE ${ }^{\mathrm{TM}}$ LDS Sample Buffer (4X), Thermo Fisher Scientific; \#NP0007) were used. Then, a wet blot and a Coomassie brilliant blue (G-250, Thermo Fisher Scientific; \#20279) staining of the membrane was applied. The horseradish peroxidase-labelled polyclonal rabbit anti-mouse antibody (Dako; \#P0260, diluted $1: 5,000)$ was provided as secondary antibody as previously described (23). For the detection of chemiluminescence the Amersham ${ }^{\mathrm{TM}}$ ECL $^{\mathrm{TM}}$ Prime Western Blotting Detection Reagent (GE Healthcare; \#12316992) was used. The analysis was performed by ChemoStar Touch v.0.5.38 (Intas Science Imaging Instruments $\mathrm{GmbH}$ ). 


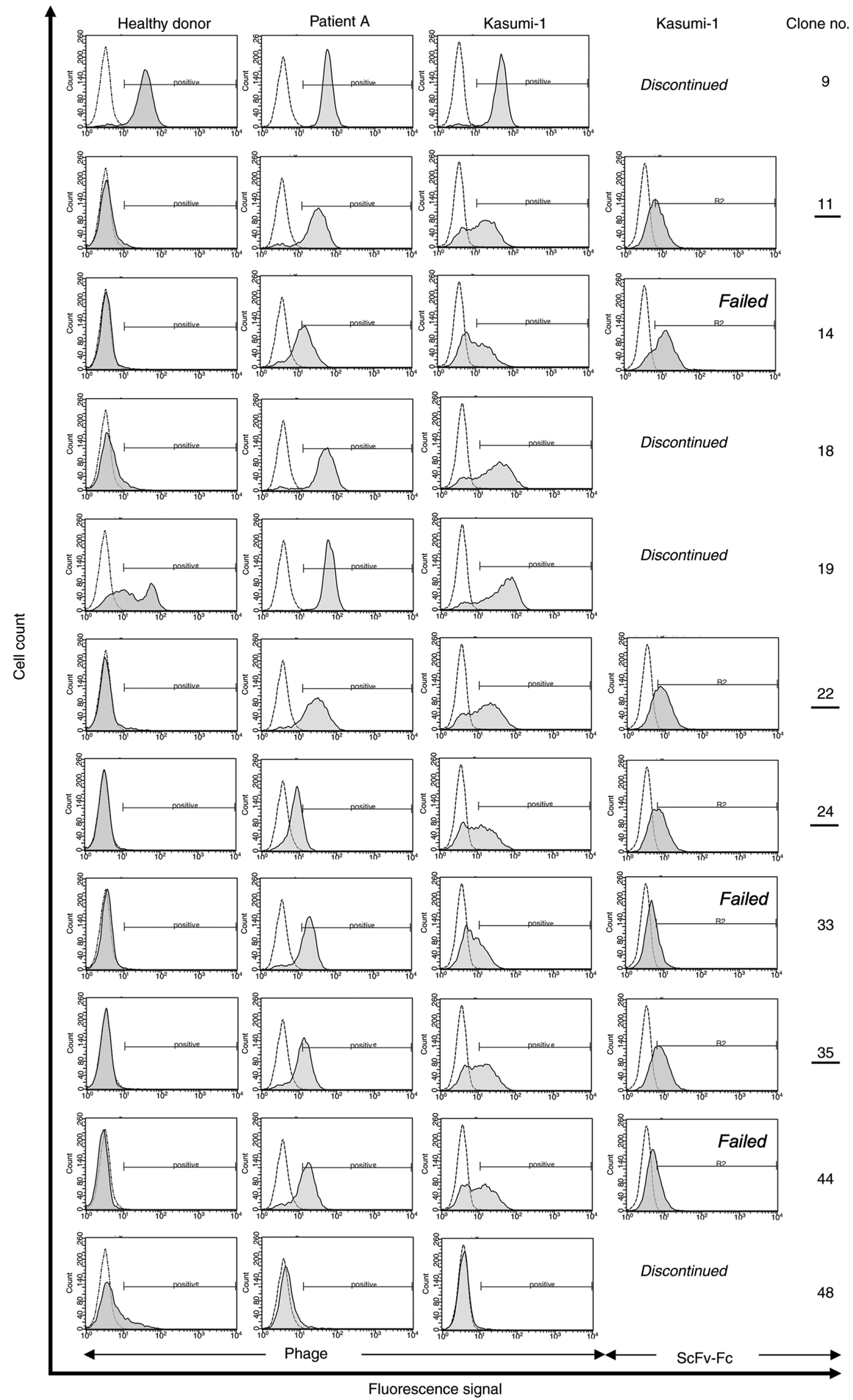

Figure 3. Flow cytometry analysis of antibody-binding to AML cells. FACS histograms (grey with continuous lines) are presented with cell counts plotted against the measured fluorescence signal. Each histogram has a positive gate defined by the horizontal line, which was set according to the negative control (white with dashed lines). Each of the columns present a different cell type: First column, healthy donor's peripheral blood cells; second column, cells from patient A; third and fourth columns, Kasumi-1 cells. The first three columns show single phage antibody-binding experiments; the last column shows a binding confirmation FACS experiment of scFv-Fc fusion proteins. The rows depict all tested clones identified by their number on the right-hand side. AML, acute myeloid leukemia; $\mathrm{scFv}-\mathrm{Fc}$, scFv cloned to a fragment crystallizable of an IgG2a mouse antibody. 
Table I. Sequence analysis of acute myeloid leukemia-binding phage clones.

A, Variable domains of the heavy chain

\begin{tabular}{lccc}
\hline Clone no. & CDR 1 & CDR 2 & CDR 3 \\
\hline 11 & GFTFSSYA & IQHLGSRT $^{\mathrm{b}}$ & AKHATSFDY \\
$14^{\mathrm{a}}$ & & IQGRGHRT $^{\mathrm{b}}$ & AKSSLVFDY $^{\mathrm{a}}$ \\
$22^{\mathrm{a}}$ & & & \\
$44^{\mathrm{a}}$ & & ITQRGSST $^{\mathrm{b}}$ & AKGTTVFDY $^{\mathrm{a}}$ \\
$24^{\mathrm{a}}$ & & & \\
$35^{\mathrm{a}}$ & & IQNRGQST $^{\mathrm{b}}$ & AKSAARFDY \\
$33^{\mathrm{a}}$ & & & \\
\hline
\end{tabular}

$\mathrm{B}$, Variable domains of the light chain

\begin{tabular}{llll}
\hline Clone no. & CDR 1 & CDR 2 & CDR 3 \\
\hline 11 & QSISSY & RAS & QQWAIVPPT \\
$14^{\mathrm{a}}$ & & RAS & QQAHTAPST \\
$22^{\mathrm{a}}$ & & YAS & QQSSLTPAT \\
$44^{\mathrm{a}}$ & & AAS & QQSYSTPNT \\
$24^{\mathrm{a}}$ & & RAS & QQYQTGPMT \\
$35^{\mathrm{a}}$ & & & QQNALAPMT \\
$33^{\mathrm{a}}$ & & NAS & QQPHTSPFT \\
\hline
\end{tabular}

${ }^{a}$ The $100 \%$ sequence identities described in detail in the main text. ${ }^{b}$ Codon exchange of the amber termination codon by inserting a glutamine codon at the position of $\mathrm{Q}$ in this sequence.

Flow cytometric analysis of $s c F v-F c$ fusion proteins. For flow cytometry analysis, $2.5 \times 10^{5}$ Kasumi- 1 cells were applied for each stain and incubated for $10 \mathrm{~min}$ at RT in $10 \%$ AB serum (diluted with WB-FACS). Then, cells were washed with $1 \mathrm{ml}$ WB-FACS and centrifuged at 2,300 rpm for $5 \mathrm{~min}$. $100 \mu \mathrm{l}$ of the supernatant of $293 \mathrm{~T}$ cells containing the $\mathrm{scFv}-\mathrm{Fc}$ fusion proteins was added and incubated for $30 \mathrm{~min}$ at $4^{\circ} \mathrm{C}$. After another washing step, $100 \mu \mathrm{l}$ gam-Fitc solution was added (dilution 1:50 in WB-FACS), cells were resuspended and incubated under the same conditions. Following a further wash step, cells were analyzed using FACS. The negative control was non-transfected supernatant (NT), while an scFv-Fc protein tested and validated in another experiment was used as positive control. The same criteria used for single phage analysis and polyclonal PD served as cut-off.

Measurement of internalization activity by flow cytometry and confocal imaging. For each stain, $2 \times 10^{5}$ Kasumi-1 cells were required. After washing $5 \mathrm{~min}$ with WB-FACS at 2,300 rpm, the cells were blocked in $10 \%$ AB serum (diluted in WB-FACS) for 10 min at RT. Subsequently, every step was conducted at $4^{\circ} \mathrm{C}$ or on ice until internalization was intended. One washing step with WB-FACS was performed at $4^{\circ} \mathrm{C}$ for each sample before resuspending with $\mathrm{scFv-Fc}$ containing supernatants. Four different antibodies (AB 11, 22, 24 and 35) were tested for internalization (Figs. 4-6).
After resuspending, samples were incubated at $4^{\circ} \mathrm{C}$ for $30 \mathrm{~min}$. Following another washing step, the cells were incubated for 15,60 and $240 \mathrm{~min}$ at $37^{\circ} \mathrm{C}, 5 \% \mathrm{CO}_{2}$, in RPMI medium with $20 \%$ FBS in order to allow internalization as described previously (23).

Internalization was stopped by adding ice-cold WB-FACS and centrifugation for $5 \mathrm{~min}$ at 2,300 rpm, $4^{\circ} \mathrm{C}$. Secondary antibody gam-Fitc was used for detection by resuspending the cell pellet in $100 \mu \mathrm{l}$ of its solution (1:50 in WB-FACS) and incubating the resulting mixture at $4^{\circ} \mathrm{C}$ for $30 \mathrm{~min}$. Following a wash step in ice-cold WB-FACS, the fluorescence signal was measured using flow cytometry. As control, non-transfected supernatant (NT) plus gam-Fitc was used. The experiment was performed three times in duplicates.

Statistical analysis. Statistical analyses were carried out using GraphPad Prism Software (Version 7.0; GraphPad Software). Results were analyzed for statistical significance using repeated measures one-way analysis of variance (ANOVA) with a Greenhouse-Geisser correction. Significance was determined at $\mathrm{P}<0.005$ (Fig. 4). The experiment was repeated three times in duplicates.

Confocal imaging preparation for internalizing experiments. For confocal imaging, Kasumi-1 cells were stained as described above. After staining, cells were resuspended in $1 \%$ paraformaldehyde diluted in WB-FACS and centrifuged $5 \mathrm{~min}$ at $700 \mathrm{rpm}$ in cytofunnels ${ }^{\mathrm{TM}}$ (Thermo Fisher Scientific; \#13127963). Subsequently, VECTASHIELD ${ }^{\circledR}$ mounting medium with DAPI (4',6-diamidino-2-phenylindole, Vector Laboratories Inc.; \#H-1200) was added and cytospins were analyzed in a confocal microscope (LSM800, Carl Zeiss AG). Analysis of scans was carried out using the Zen 2.3 software (Carl Zeiss AG) (Fig. 6).

\section{Results}

Standardization and optimization of cell-based panning protocols. Cell-based phage display panning procedures using primary tumor cells are the optimal methods for the discovery of antibodies against tumor-associated surface antigens because target antigens are displayed in their natural configuration and with post-translational modifications (27). Several protocols for whole cell panning using leukemic cells have been reported, but these describe a variety of screening strategies $(19,21,22,28-31)$. To examine these differences, existing articles are briefly summarized and compared based on their technical approaches to cell-based panning procedures.

First, the number of selection rounds (SR) varied between two $(21,22)$ and five $(29)$. Second, panning material applied during the SRs differed substantially regarding cell counts and types of cells: Only one laboratory used patients' primary cells during the entire selection procedure (29), although these cells originated from a patient with chronic myelogenous leukemia (CML) in blast crisis. Two articles described partial use of primary AML blasts during cell panning in combination with AML cell lines and a mixture of AML/CML-derived cell lines, respectively (22). Third, a subtractive panning strategy by including a depletion step (DS) was described in multiple publications $(19,21,22)$, but these DS varied concerning 
Table II. Sequences of primers used for site-directed mutagenesis.

Primer name

Sequence, 5'-3'

Used for clone no.

AML_WT_11_T

AML_WT_11_B

AML_WT_14_T

AML_WT_14_B

AML_WT_24_T

AML_WT_24_B

AML_WT_33_T

AML_WT_33_B
GAGTGGGTCTCAAGTATTcAGCATTTGGGTTCGCGG

CCGCGAACCCAAATGCTgAATACTTGAGACCCACTC

GAGTGGGTCTCAACGATTcAGGGGCGTGGTCATAGG

CCTATGACCACGCCCCTgAATCGTTGAGACCCACTC

GGAGTGGGTCTCAACTATTACTcAGCGGGGTAGTAG

CTACTACCCCGCTgAGTAATAGTTGAGACCCACTCC

GATTCAGAATCGTGGTcAGAGTACAGCGTACGCAGA

TCTGCGTACGCTGTACTCTgACCACGATTCTGAATC
11

$14,22,44$

The base written in lower case indicates the position of site-directed mutagenesis. AML, acute myeloid leukemia.

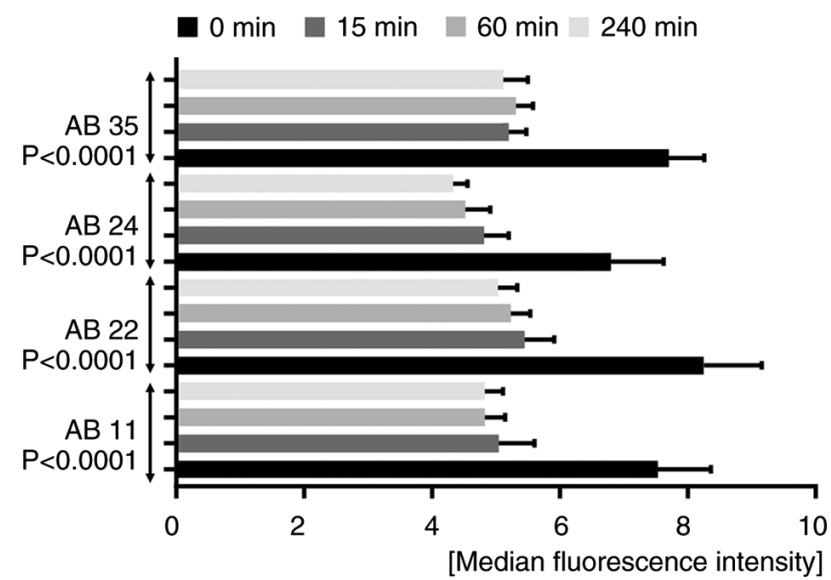

Figure 4. Internalizing activity measured by flow cytometry. A time-dependent bar chart presents the fluorescence signal quenching of the tested antibodies AB 11, 22, 24 and 35. Bar graphs for each antibody indicate a decrease in fluorescence signals the longer the internalization time. The measurements were performed before internalization $(0 \mathrm{~min})$ and after internalization times of 15, 60 and $240 \mathrm{~min}$. All four antibodies showed statistical significance using a repeated measures one-way ANOVA with a Greenhouse-Geisser correction $[\mathrm{AB} 11, \mathrm{~F}(1.851,9.253)=75.65, \mathrm{P}<0.0001$; $\mathrm{AB} 22, \mathrm{~F}(1.133,5.664)=131.3, \mathrm{P}<0.0001 ; \mathrm{AB} 24, \mathrm{~F}(2.041,10.21)=39.28$, $\mathrm{P}<0.0001 ; \mathrm{AB} 35, \mathrm{~F}(1.296,6.478)=102,7, \mathrm{P}<0.0001]$. AB, antibody.

handling of the healthy donors' cells: Peripheral blood cells (PBC) were either acquired by buffy coat $(21,22)$ or as membrane fragments after DGC (19).

In summary, in view of the variety of existing technical approaches, we standardized the number of selection rounds by restricting them to exactly three. Moreover, we used AML patients' cells throughout the whole cell-based panning process and found that initial blast cell counts played an important role in determining the outcome of phage antibody selection. Finally, we demonstrated the impact of optimizing the diversity of depletion antigens and were able to isolate four promising, AML blast-binding and internalizing antibodies.

Positive Selection: Initial AML blast counts are associated with polyclonal enrichment of specific phage antibodies. Regarding the selection process of patient 0 , no enrichment of specific binders during polyclonal PD was observed in FACS analysis. Patient 0 had blast percentages of 52\% after DGC and was not treated via CD34 MACS, but rather used as control in comparisons with CD34 sorted selection procedures (Fig. 1).

In contrast to patient 0 , all other selection strategies showed polyclonal enrichment of specific phage antibody binders ranging from $93.4 \%$ (patient D) to $10.1 \%$ (patient B) (Fig. 2). Of these, only patient D's cells were not magnetically sorted because of their blast portion of $96 \%$, which made $\mathrm{CD} 34^{+}$cell enrichment unnecessary (Fig. 1). Patient $\mathrm{C}$ exhibited blast percentages of $76 \%$ after DGC and was therefore only sorted during the first SR (Fig. 1).

Because the first SR proved to be the most important round for selecting binders $(16,32)$, the first SR always underwent CD34 enrichment. Using flow cytometry analysis as described below, we identified that the purity of patient C's enriched blasts during the first SR was 99\%. Patient A and B were sorted during all three SRs and reached average purities of 95 and $96 \%$, respectively, in FACS analysis. To the best of our knowledge, this is the first report using CD34-enriched blast cells for cell- based panning procedures.

Negative selection: Diversity of depletion antigens influences outcomes of cell-based selection procedures. Patient 0 's depletion step (DS) consisted of DGC, a procedure, which excludes granulocytes and erythrocytes and preserves mononuclear cells only, e.g., lymphocytes and monocytes (33). Thus, less antigen diversity (AD) was available during this DS than in the DS of patient B, C and D (Fig. 1, here an increase in antigen diversity is shown by an increase in size of the grey ramp in the background).

Although patient A had the same DS as patient 0, patient A showed polyclonal enrichment of AML blast-binding phage particles (Fig. 2). The sole difference between both selection procedures was that patient A was CD34-sorted for panning. In contrast to patient 0 and $A$, the depletion procedures of patient $\mathrm{B}, \mathrm{C}$ and $\mathrm{D}$ were carried out by human, erythrocyte-lysed peripheral blood cells. Hence, nothing but erythrocytes were excluded. Consequently, AD was higher in their DS compared with the negative selection of patient 0 and A (Fig. 1).

However, the highest AD was observed during patient D's selection procedure because of its additional DS with enriched monocytes (Fig. 1). Here, only one clone was selected which bound AML blasts, but all portions of healthy blood cells as 

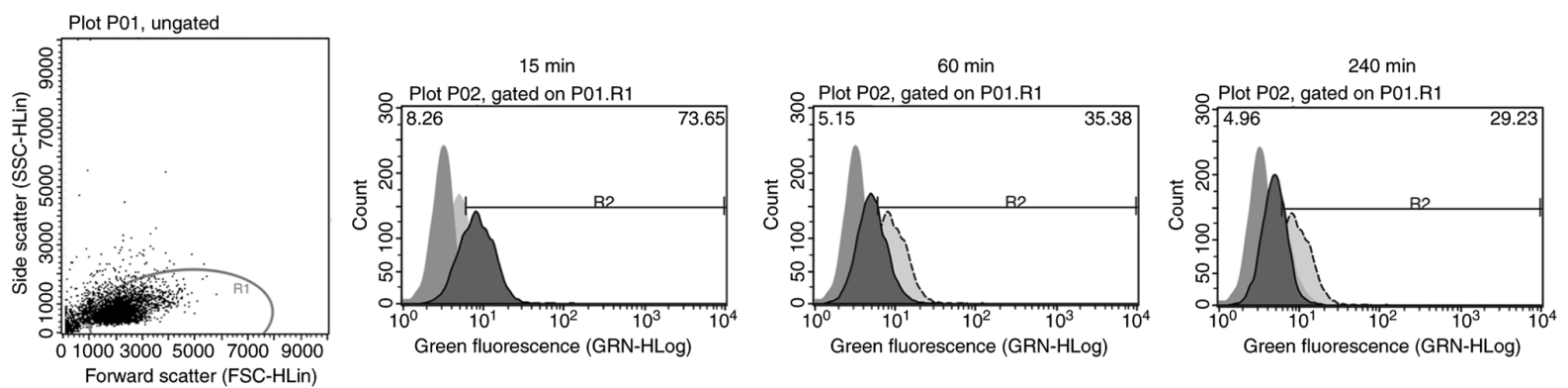

Figure 5. Internalizing activity of antibody 22 measured by flow cytometry. Time-dependent fluorescence signal reduction presented for antibody 22 . Plot P01 demonstrates the initial gating plot of Kasumi-1 cells. Plot P02 is depicted in a time dependent manner at 15,60 and 240 min. The dark grey graph with continuous line shows in each P02 the measurement of the specific time point. The middle grey graph without border is the control; the light grey with dashed lines is depicted for comparison reasons and shows the 15 min measurement; the lighter grey without any border shows the 60 min measurement. In the top right-hand corner, the percentage of cells in the positive gate defined by R2 is depicted. In the top left-hand corner, the median fluorescence of the specific measurement is shown. This experiment was performed in triplicate.

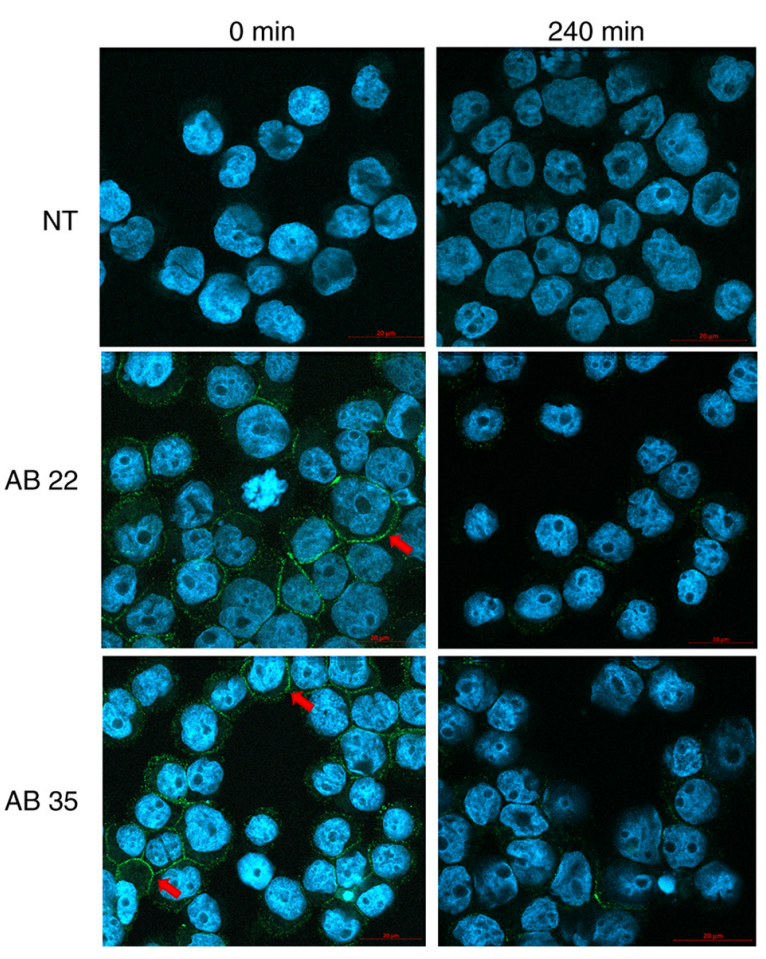

Figure 6. Internalizing activity shown by confocal imaging. Confocal images are presented to illustrate the binding and cellular uptake of $\mathrm{AB} 22$ and 35. The bright initial fluorescence signal of the cell membranes (red arrow) at $0 \mathrm{~min}$ in contrast to the fluorescence signal after $240 \mathrm{~min}$ is shown. NT was used as the negative control. Red arrows emphasize the membrane fluorescence signal of Kasumi- 1 cells. Scale, $20 \mu \mathrm{m}$. AB, antibody; NT, supernatant of non-transfected 293T.

well (Fig. 1). Consequently, this clone had overgrown all other more specific phages during the selection strategy and thus, was not pursued further (Fig. 3, clone no. 9).

In conclusion, medium levels of $\mathrm{AD}$ during the depletion strategies of patient $\mathrm{B}$ and $\mathrm{C}$ entailed the most specific AML-binding phages as confirmed by monoclonal analysis and sequencing, respectively.

Panning-enriched antibody clones contain consensus sequences. After confirmation of polyclonal enrichment of phage particles, randomly selected single antibody clones from the third SR of the successful selection methods were tested for monoclonal binding activity (Fig. 1). To do so, 352 samples were investigated for each patient individually (A, B, C and D) by flow cytometry. FACS-positive binders, ( 8 out of 352 for patient A, 25 out of 352 for patient B, 10 out of 352 for patient $C$, and 10 out of 352 for patient D) were DNA sequenced ( $\sum 53$ sequenced phages; Fig. 1). Comparisons of these sequences and alignments with publicly available sequence databases (NCBI, https://blast.ncbi.nlm.nih.gov/Blast.cgi) revealed a total of 11 unique antibody clones.

Based on their similarity, three out of these 11 clones contained shared sequence identities, especially in the CDR2 and CDR3 sequences of their heavy chain. Interestingly, clones with shared sequence identities were isolated from different depletion and selection strategies and thus, were called consensus phages. Seven of the 11 tested phage antibodies were positive for AML blasts (Fig. 3), but negative for healthy blood cells. Subsequently, all blast-specific candidates were expressed as soluble $\mathrm{scFv-Fc}$ fusion protein antibodies (AB 11, 14, 22, 24, 33, 35 and 44) and further investigated regarding their binding and internalizing activity. Two of these candidates were former consensus phages (AB 33, AB 35).

In addition, all seven clones contained an amber termination codon (TAG) in the DNA sequence of every CDR2 of their immunoglobulin heavy chain, which was changed by site- directed mutagenesis to CAG (Glutamine, Q) (Table I).

Moreover, homologies of heavy chain sequences were noticed between AB 24 and 35, as well as between AB 14, 22 and 44. Intriguingly, AB 24 and 35 differed only in the CDR3 portion of their immunoglobulin light chain (Table I).

Effective tumor cell-binding activity against primary AML blasts and the human AML cell line Kasumi-1. Specific binding activity of selected antibody clones was analyzed on Kasumi-1 cells and primary AML blasts using scFv-presenting phage particles as well as soluble fusion protein (Fig. 3). After functional protein expression, clones $\mathrm{AB} 33$ and 44 failed to meet our binding criteria and were therefore not pursued. In addition, AB 14 showed unspecific binding activity on 293T cells and was therefore also not pursued.

Cellular internalization of the $s c F v-F c$ fusion proteins. Internalizing activity was observed for antibody clones $\mathrm{AB}$ $11,22,24$ and 35 via flow cytometry and confocal imaging 
using Kasumi-1 cells (Figs. 4-6). All four antibodies showed a reduction of fluorescence signals by increasing internalization time. This reduction showed statistical significance $(\mathrm{P}<0.0001)$ for each tested antibody [AB $11(\mathrm{n}=6), \mathrm{F}(1.851,9.253)=75.65$, $\mathrm{P}<0.0001 ;$ AB $22(\mathrm{n}=6), \mathrm{F}(1.133,5.664)=131.3, \mathrm{P}<0.0001$; AB $24(n=6), F(2.041,10.21)=39.28, P<0.0001 ;$ AB $35(n=6)$, $\mathrm{F}(1.296,6.478)=102,7, \mathrm{P}<0.0001$; Fig. 4]. Confocal imaging confirmed and visualized the internalizing activity of all tested antibodies (Fig. 6).

\section{Discussion}

The fundamental rationale for the implementation of antibody-based targeted therapies in cancer relies on their sophisticated ability to selectively tackle cancerous populations while leaving healthy cells alone. However, the identification of highly selective cell surface biomarkers capable of discriminating between benign and malignant cells is an enormous experimental challenge. Standard selection procedures performed by immobilization of recombinant target proteins or cell membrane fractions on plastic surfaces may not be sufficient to meet this challenge because of significantly altering protein conformations (34), so that isolated antibodies may not bind the native conformation of targeted antigens efficiently. Thus, experimental strategies, which account for three-dimensional structures of cell surface antigens, seem more promising.

In this context, we implemented intact primary AML blasts as complex source of targetable antigens for the selection of specific antibodies against acute myeloid leukemia, thus preserving the native conformational structure of membrane antigens (35). However, primary tumor cell-based panning techniques are often hampered by low abundance of blast-specific antigens, which discriminate healthy from tumorous cells against a background of irrelevant antigens (36).

Additionally, a major difficulty in working with primary blasts instead of e.g., human cell lines is their variable ratio in patients' bloods, which seldom reach $100 \%$ of all cells. Thus, we implemented a blast enrichment step in consideration of patients' initial blast percentages, making PD selection procedures feasible for patients regardless their blast counts. Moreover, we established novel depletion strategies to exclude irrelevant and healthy antigens from positive selection steps and, thereby, showed that the diversity of depletion antigens has a major impact on individual selection outcomes (Fig. 1).

An essential prerequisite for phage display success is significant enrichment of specific phage particles during consecutive biopanning rounds. Up to four selection rounds are typically performed to allow strong accumulation of antigen-specific phages without losing phage diversity (37). In line with this approach, we carried out three subsequent rounds of panning in our experiments.

Relative to the considerations above, we determined that initial counts of at least $75 \%$ primary blasts after DGC are critical for successful whole cell-based panning using primary tumor cells. For blast counts below this threshold, we recommend a blast enrichment step before panning. By contrast, blast counts above $90 \%$ did not benefit from enrichment in our experiments.
For enrichment, we established a strategy to achieve highly concentrated CD34+ blasts. CD34 is well-known as marker of hematopoietic stem cells (HSC) and hematopoietic progenitor cells (24). It is expressed in roughly $40 \%$ of all AML cases (38). By contrast, CD33, the myeloid antigen marker of the commercially available antibody conjugate gemtuzumab-ozogamicin (GO) (39), is expressed in $~ 75 \%$ of AMLs in adults, but has response rates up to $30 \%$ only, suggesting a heterogeneous expression of CD33 by AML cells (40). Interestingly, it was the most primitive progenitor compartment (as indicated by $\mathrm{CD} 34$ expression) which showed reduced response rates to GO (41) as well as overall reduced surface expression of CD33 in vitro (40). Thus, targeting CD34+ leukemic cells is a promising candidate approach for the complementation of CD33-based antibody therapies in AML.

To the best of our knowledge, the CD34 enrichment approach described here is the first report of the individual generation of novel antibodies for AML patients regardless of their initial blast counts. The relevance of this step was demonstrated in patient 0 's PD procedure, which did not include an enrichment step despite initial blast counts below the cut-off value and subsequently failed to achieve accumulation of specific phage particles (Fig. 2). Future studies will be needed to determine whether other surface antigens, e.g., the transmembrane protein receptor CD117 (42), can also be implemented for our suggested blast enrichment procedure.

For identification of novel blast-specific binders, the phage antibody library Tomlinson $\mathrm{J}$ was initially depleted against equivalent non-cancerous blood cells (43). This negative selection (depletion step) was introduced prior to positive selection to remove binders directed against unspecific antigens, which are expressed on the surface of both benign and malignant cells. It has been reported that insufficient depletion can reduce the success of the biopanning procedure (15). However, our literature research showed that depletion is not performed using a standardized procedure or not at all, indicating that optimization of the depletion step could be an effective method to improve panning results. Therefore, we investigated the impact of three depletion strategies on antigen diversity (AD) and, thus, overall selection success. The following strategies (in ascending order of antigen diversity) were analyzed: density gradient centrifugation (DGC), lysis of erythrocytes (LE) and lysis of erythrocytes plus enrichment of monocytes by adherence (MA).

The quantity of different antigens was determined by the addition or overrepresentation of different cell populations. Thus, DGC retained only PBMCs, i.e., lymphocytes and monocytes, LE contained the populations specified above plus granulocytes and MA included the same cell fractions as LE, but additionally enriched monocytes, a minor cell fraction in blood. This monocytic enrichment was conducted based on reports of similar antigens on myelomonocytic leukemia (FAB M4) and monoblastic/monocytic leukemia (FAB M5) cells (44). We initially hypothesized that the enrichment of blast-specific antibodies is correlated to antigen diversity. However, our experiments did not support this hypothesis as the strategy with the highest diversity depletion antigens (patient D) retained just one single phage, which also bound all populations of healthy donor cells (Fig. 3, clone 9). According to Smith and Petrenko (16), stringency is a possible 
reason for the failure of high abundancies of DA when the attempt to force enrichment of target-specific phage is made by presenting a large diversity of depletion antigens, especially during the first SR, where merely 100 phage antibodies per unique clone are present (16). This approach can cause target-specific phages to be lost in the background of unspecific interactions between phages, cells and antigens (16).

On the other hand, shown by the experiments on material from patient 0 and patient A (Fig. 1), inadequate DA levels can result in an abundance of unabsorbed, but unspecific phages (15). The PD procedure using material from patient 0 did not result in any specific phage and patient A supplied only one.

In conclusion, we recommend using medium levels of antigen diversity provided by lysis of erythrocytes containing normal blood compositions of cellular antigens to retain most specific phage antibodies.

To determine the number of different antibody clones that bound specifically to AML blast cells, 53 FACS-positive clones were characterized by DNA sequencing and aligned. This analysis revealed 11 unique sequences and a significant enrichment of consensus sequences in the variable regions of the heavy and light chains. To categorize these findings, the synthesis process of the applied PD library has to be considered, as the naïve human semi-synthetic Tomlinson J library is mutated only in the complementarity determining region 2 (CDR2) and CDR3 of the variable parts of the light chain (VL) as well as the heavy chain (VH) (45). Consequently, both CDR1s are maintained throughout the whole PD library. Consequently, certain degrees of sequence limitations and, thus, restrictions regarding the diversity of phage antibodies become obvious. For example, Tomlinson $\mathrm{J}$ seems to be prone to the selection of amber codon bearing phages (46-48), roughly $\sim 45 \%$ caused by its random synthesis process utilizing an NNK triplet codon bias (i.e., $\mathrm{N}=\mathrm{A}, \mathrm{T}, \mathrm{G}$, or $\mathrm{C}$ and $\mathrm{K}=\mathrm{T}$ or $\mathrm{G}$ ) (49).

Moreover, we found identical sequences of $\mathrm{VH}$ between phage antibodies (PH) 14, $\mathrm{PH} \mathrm{22,} \mathrm{and} 44$ as well as sequence identities between PH 24 and 35, whereas the last two phage antibodies differed only regarding their CDR3 of VL (Table I). Such sequence identities seemed to occur frequently during PD selection strategies performed by the Tomlinson $\mathrm{J}$ library. For example, Fitting et al (19) also used the Tomlinson library and retained two antibodies containing the same VL, but different VH. Moreover, Huang et al (50) were confronted with identical $\mathrm{VH}$ sequences of in total five antibody clones by using the Tomlinson PD library. Huang et al also reported identical sequences in two clones with the exception of CDR3 of VL (50).

Interestingly, in our study, three unique phage antibodies were selected in independent selection procedures of different AML patients (Fig. 1, indicated by the shared sequences in box brackets). Thus, we termed them consensus phages ( $\mathrm{PH} 9$, PH 33, PH 35).

Several explanation approaches can be taken for the phenomenon of consensus phages: First, loss of diversity can happen during the amplification process between selection rounds, leading to so-called propagation-related phage particles $(37,51,52)$. These particles are biologically enriched for reasons including intrinsic advantages regarding the assembly process of phages bearing special fusion proteins (53), improved binding of phages to the bacterial pili (15), and mutations in regulatory regions of phage genes $(52,54)$. Consequently, Vodnik et al (51) described this phenomenon as almost intrinsic to phage display technology.

Second, consensus phages may bind contents of the experimental setting i.e., buffers, blocking reagents, plastic tubes, et cetera $(52,55)$ and, therefore, be subject to selectionprocedure-related enrichment (51).

Third, the target itself may favor the enrichment of consensus phages (16).

In our experiments, all three explanations may have contributed as combination of target-induced selection pressure, comparable experimental conditions and uniform bacterial production conditions.

Moreover, Sasso et al (56) performed ten selection procedures with comparable in vitro conditions and reported several clones commonly enriched in all ten selection procedures. Nevertheless, these clones were deemed unspecific without further investigation (56).

By contrast, we explored the potential of our consensus phage $\mathrm{PH} 35$ further and showed its blast-binding ability after conversion into an scFv-Fc antibody format as well as its internalizing activity (Figs. 3, 4 and 6). Additionally, clones 11, 22 , and 24 showed internalizing activity; showing that they are potential candidates for antibody-drug conjugate in AML immunotherapy (57).

The first limitation of this study is the lack of sufficient patient material for antibody selection and therefore, we were not able to perform all selection strategies with the same patient. Second, our implemented CD $34^{+}$enrichment step is dependent on the CD34 antigen expression of primary blast cells. However, only $40 \%$ of AML cells express this antigen on their cell surface. Thus, future studies will be needed to determine whether other surface antigens, e.g., CD117, can also be implemented for the blast enrichment procedure.

Third, the semi-synthetic Tomlinson library is based on one single human framework ( $\mathrm{VH}-3$ and $\mathrm{V} \kappa-1)$ and thus, is restricted by the selected $\mathrm{V}$-genes. When using a complete naïve antibody library that includes all human frameworks, there is a much greater chance for isolation of high-potent antibodies.

In summary, we presented a CD34-based enrichment strategy, which improves the standard cell-based panning procedures for the generation of AML blast-specific internalizing antibodies, thus potentially providing AML patients with access to personalized antibodies irrespective of their initial blast counts.

In addition, we explored depletion strategies with increasing levels of depletion antigens regarding their impact on PD selection outcomes and found that medium levels of depletion antigens were most effective to isolate promising phage antibodies.

Finally, we discovered sequence similarities between our selected phage antibodies, indicating a common observation when using the semi-synthetic Tomlinson library.

After conversion of the isolated candidate $\mathrm{scFv}$ antibody fragments into scFv-Fc fusion proteins we found that four of these internalized successfully into cells of the AML-derived cell line Kasumi-1, which makes them potential candidates for immunotherapeutic agents. 


\section{Acknowledgements}

Not applicable.

\section{Funding}

The Justus Liebig University Trainee Program for young medical scientists funded this work.

\section{Availability of data and materials}

The datasets used and/or analyzed during the current study are available from the corresponding author on reasonable request.

\section{Authors' contributions}

TW conceived the clinical and experimental concept, performed the lab experiments and analyzed the data. TW performed the literature research and prepared the manuscript. MKT and TW revised the manuscript. SP supported all lab experiments and critically verified the correct execution. SG, MR, WB, UG, ATS and NR evaluated and discussed all lab results thoroughly. MR and WB supported the clinical setting and enrollment of patients with AML. SG and MKT provided lab material, discussed and interpretated the study results and provided their expertise for the successful outcome of this study. MKT, SP, WB and TW confirm the authenticity of all the raw data. All authors have read and approved the final manuscript.

\section{Ethics approval and consent to participate}

All patients with AML gave written informed consent, and the Clinical Ethics Committee of the Justus Liebig University (Giessen, Germany) approved all experimental work (approval no. 140/16). Furthermore, AB serum was received from patients after written informed consent, which was also approved by the Clinical Ethics Committee of the Justus Liebig University Giessen (approval no. 05/00).

\section{Patient consent for publication}

All patients gave written informed consent.

\section{Competing interests}

The authors declare that they have no competing interests.

\section{References}

1. Medinger M, Lengerke $\mathrm{C}$ and Passweg J: Novel therapeutic options in acute myeloid leukemia. Leuk Res Rep 6: 39-49, 2016.

2. Southam CM, Craver LF, Dargeon HW and Burchenal JH: A study of the natural history of acute leukemia with special reference to the duration of the disease and the occurrence of remissions. Cancer 4: 39-59, 1951.

3. Juliusson G, Antunovic P, Derolf A, Lehmann S, Mollgard L, Stockelberg D, Tidefelt U, Wahlin A and Höglund M: Age and acute myeloid leukemia: Real world data on decision to treat and outcomes from the Swedish acute leukemia registry. Blood 30: 4179-4187, 2009.
4. Berger DP, Mertelsmann R, Duyster J, Tumorzentrum FreiburgCCCF (eds). Das Rote Buch: Hämatologie und internistische Onkologie. Überarbeitete und erweiterte Auflage. Landsberg am Lech: ecomed Medizin, p1400, 2017.

5. Patel JP, Gönen M, Figueroa ME, Fernandez H, Sun Z, Racevskis J, Van Vlierberghe P, Dolgalev I, Thomas S, Aminova $\mathrm{O}$, et al: Prognostic relevance of integrated genetic profiling in acute myeloid leukemia. N Engl J Med 22: 1079-1089, 2012

6. Papaemmanuil E, Gerstung M, Bullinger L, Gaidzik VI, Paschka P, Roberts ND, Potter NE, Heuser M, Thol F, Bolli N, et al: Genomic classification and prognosis in acute myeloid leukemia. N Engl J Med 9: 2209-2221, 2016.

7. Cancer Genome Atlas Research Network; Ley TJ, Miller C, Ding L, Raphael BJ, Mungall AJ, Robertson AG, Hoadley K, Triche TJ Jr, Laird PW, et al: Genomic and epigenomic landscapes of adult de novo acute myeloid leukemia. N Engl J Med 30: 2059-2074, 2013.

8. Talati C and Sweet K: Recently approved therapies in acute myeloid leukemia: A complex treatment landscape. Leuk Res 73: 58-66, 2018.

9. Dugan J and Pollyea D: Enasidenib for the treatment of acute myeloid leukemia. Expert Rev Clin Pharmacol 3: 755-760, 2018.

10. Pollyea DA: New drugs for acute myeloid leukemia inspired by genomics and when to use them. Hematology Am Soc Hematol Educ Program 30: 45-50, 2018.

11. Egan PC and Reagan JL: The return of gemtuzumab ozogamicin: A humanized anti-CD33 monoclonal antibody-drug conjugate for the treatment of newly diagnosed acute myeloid leukemia. Onco Targets Ther 11: 8265-8272, 2018.

12. McCafferty J, Griffiths AD, Winter G and Chiswell DJ: Phage antibodies: Filamentous phage displaying antibody variable domains. Nature 348: 552-524, 1990.

13. Breitling F, Dübel S, Seehaus T, Klewinghaus I and Little M: A surface expression vector for antibody screening. Gene 15: 147-153, 1991.

14. Frei JC and Lai JR: Protein and antibody engineering by phage display. Methods Enzymol 5806: 45-87, 2016.

15. Barbas III CF, Burton DR, Scott JK and Silverman GJ: Phage Display: A Laboratory Manual. Cold Spring Harbor Laboratory, New York, NY, 2004.

16. Smith GP and Petrenko VA: Phage display. Chem Rev 97: 391-410, 1997.

17. Tur MK, Rothe A, Huhn M, Goerres U, Klimka A, Stöcker M, Engert A, Fischer R, Finner R and Barth S: A novel approach for immunization, screening and characterization of selected $\mathrm{scFv}$ libraries using membrane fractions of tumor cells. Int J Mol Med 11: 523-527, 2003.

18. Ten Haaf A, Gattenlöhner S and Tur MK: Antibody selection on FFPE tissue slides. Methods Mol Biol 1701: 381-391, 2018.

19. Fitting J, Blume T, Ten Haaf A, Blau W, Gattenlöhner S, Tur MK and Barth S: Phage display-based generation of novel internalizing antibody fragments for immunotoxin-based treatment of acute myeloid leukemia. MAbs 7: 390-402, 2015.

20. Ljungars A, Svensson C, Carlsson A, Birgersson E, Tornberg UC, Frendéus B, Ohlin M and Mattsson M: Deep mining of complex antibody phage pools generated by cell panning enables discovery of rare antibodies binding new targets and epitopes. Front Pharmacol 10: 847, 2019.

21. Bakker ABH, van den Oudenrijn S, Bakker AQ, Feller N, van Meijer M, Bia JA, Jongeneelen MA, Visser TJ, Bijl N, Geuijen CA, et al: C-type lectin-like molecule-1: A novel myeloid cell surface marker associated with acute myeloid leukemia. Cancer Res 15: 8443-8450, 2004.

22. Geuijen CAW, Bijl N, Smit RCM, Cox F, Throsby M, Visser TJ, Jongeneelen MA, Bakker AB, Kruisbeek AM, Goudsmit J and de Kruif J: A proteomic approach to tumour target identification using phage display, affinity purification and mass spectrometry. Eur J Cancer 41: 178-187, 1990.

23. ten Haaf A, Pscherer S, Fries K, Barth S, Gattenlöhner S and Tur MK: Phage display-based on-slide selection of tumor-specific antibodies on formalin-fixed paraffin-embedded human tissue biopsies. Immunol Lett 166: 65-78, 2015.

24. Sidney LE, Branch MJ, Dunphy SE, Dua HS and Hopkinson A: Concise review: Evidence for CD34 as a common marker for diverse progenitors. Stem Cells 32: 1380-1289, 2014.

25. Leach RM, Drummond M, Doig A, McKay P, Jackson B and Bain BJ: Practical Flow Cytometry in Haematology: 100 worked examples. John Wiley and Sons, Inc., Hoboken, NJ, 2015. 
26. Fitting J, Killian D, Junghanss C, Willenbrock S, Escobar HM, Lange S, Nolte I, Barth S and Tur MK: Generation of recombinant antibody fragments that target canine dendritic cells by phage display technology. Vet Comp Oncol 9: 183-195, 2011.

27. Sánchez-Martín D, Sørensen MD, Lykkemark S, Sanz L, Kristensen P, Ruoslahti E and Álvarez-Vallina L: Selection strategies for anticancer antibody discovery: Searching off the beaten path. Trends Biotechnol 33: 292-301, 2015.

28. Jäger S, Jahnke A, Wilmes T, Adebahr S, Vögtle FN Delima-Hahn E, Pfeifer D, Berg T, Lübbert $M$ and Trepel M: Leukemia-targeting ligands isolated from phage-display peptide libraries. Leukemia 21: 411-420, 2007.

29. Galili N, Devemy E and Raza A: Isolation of specific and biologically active peptides that bind cells from patients with acute myeloid leukemia (AML). J Hematol Oncol 10: 8, 2008

30. Karjalainen K, Jaalouk DE, Bueso-Ramos CE, Zurita AJ, Kuniyasu A, Eckhardt BL, Marini FC, Lichtiger B, O'Brien S, Kantarjian HM, et al: Targeting neuropilin-1 in human leukemia and lymphoma. Blood 20: 920-927, 2011.

31. Nodehi SM, Repp R, Kellner C, Bräutigam J, Staudinger M, Schub N, Peipp M, Gramatzki M and Humpe A: Enhanced ADCC activity of affinity maturated and $\mathrm{Fc}$-engineered mini-antibodies directed against the AML stem cell antigen CD96. PLoS One 7: e42426, 2012.

32. Hoen PA, Jirka SM, ten Broeke BR, Schultes EA, Aguilera B, Pang KH, Heemskerk H, Aartsma-Rus A, van Ommen GJ and den Dunnen JT: Phage display screening without repetitious selection rounds. Anal Biochem 421: 622-631, 2012.

33. Luttmann W, Bratke K, Küpper M and Myrtek D: Der Experimentator: Immunologie. Springer, Heidelberg, 2014.

34. Ngai PK, Ackermann F, Wendt H, Savoca R and Bosshard HR Protein A antibody-capture ELISA (PACE): An ELISA format to avoid denaturation of surface-adsorbed antigens. J Immunol Methods 158: 267-276, 1993

35. Nikfarjam S, Tohidkia MR, Mehdipour T, Soleimani R, Rahimi AA and Nouri M: Successful application of whole cell panning for isolation of phage antibody fragments specific to differentiated gastric cancer cells. Adv Pharm Bull 9: 624-631, 2019.

36. Jones ML, Alfaleh MA, Kumble S, Zhang S, Osborne GW, Yeh M, Arora N, Hou JJ, Howard CB, Chin DY and Mahler SM: Targeting membrane proteins for antibody discovery using phage display. Sci Rep 6: 26240, 2016.

37. Derda R, Tang S, Li SC, Ng S, Matochko W and Jafari MR: Diversity of phage-displayed libraries of peptides during panning and amplification. Molecules 21: 1776-1803, 2011.

38. Naeim F, Nagesh Rao P, Song SX and Phan RT: Principles of Immunophenotyping. In: Atlas of Hematopathology. Elsevier, pp29-56, 2018.

39. Ricart AD: Antibody-drug conjugates of calicheamicin derivative: Gemtuzumab ozogamicin and inotuzumab ozogamicin. Clin Cancer Res 15: 6417-6427, 2011.

40. Vercauteren SM, Zapf R and Sutherland HJ: Primitive AML progenitors from most CD34(+) patients lack CD33 expression but progenitors from many CD34(-) AML patients express CD33. Cytotherapy 9: 194-204, 2007.

41. Matsui H, Takeshita A, Naito K, Shinjo K, Shigeno K, Maekawa M, Yamakawa Y, Tanimoto M, Kobayashi M, Ohnishi K and Ohno R: Reduced effect of gemtuzumab ozogamicin (CMA-676) on P-glycoprotein and/or CD34-positive leukemia cells and its restoration by multidrug resistance modifiers. Leukemia 16: 813-819, 2002
42. Wells SJ, Bray RA, Stempora LL and Farhi DC: CD117/CD34 expression in leukemic blasts. Am J Clin Pathol 1: 192-195, 1996.

43. Alfaleh MA, Jones ML, Howard CB and Mahler SM: Strategies for selecting membrane protein-specific antibodies using phage display with cell-based panning. Antibodies (Basel) 5: 10, 2017.

44. Xu Y, McKenna RW, Wilson KS, Karandikar NJ, Schultz RA and Kroft SH: Immunophenotypic identification of acute myeloid leukemia with monocytic differentiation. Leukemia 20: 1321-1324, 2006

45. Reader RH, Workman RG, Maddison BC and Gough KC: Advances in the production and batch reformatting of phage antibody libraries. Mol Biotechnol 61: 801-815, 2019.

46. Pokorny NJ, Boulter-Bitzer JI, Hall JC, Trevors JT and Lee H: Inhibition of Cryptosporidium parvum infection of a mammalian cell culture by recombinant $\mathrm{scF}$ v antibodies. Antonie Van Leeuwenhoek 94: 353-364, 2008.

47. Wu S, Ke A and Doudna JA: A fast and efficient procedure to produce scFvs specific for large macromolecular complexes. J Immunol Methods 318: 95-101, 2007.

48. Boulter-Bitzer JI, Lee H and Trevors JT: Single-chain variable fragment antibodies selected by phage display against the sporozoite surface antigen P23 of cryptosporidium parvum. J Parasitol 95: 75-81, 2009.

49. Marcus WD, Lindsay SM and Sierks MR: Identification and repair of positive binding antibodies containing randomly generated amber codons from synthetic phage display libraries. Biotechnol Prog 2: 919-922, 2006.

50. Huang W, Samanta M, Crawford SE, Estes MK, Neill FH, Atmar RL and Palzkill T: Identification of human single-chain antibodies with broad reactivity for noroviruses. Protein Eng Des Sel 27: 339-349, 2014

51. Vodnik M, Zager U, Strukelj B and Lunder M: Phage display: Selecting straws instead of a needle from a haystack. Molecules 19: 790-817, 2011

52. Thomas WD, Golomb M and Smith GP: Corruption of phage display libraries by target-unrelated clones: Diagnosis and countermeasures. Anal Biochem 407: 237-240, 2010.

53. Kuzmicheva GA, Jayanna PK, Sorokulova IB and Petrenko VA: Diversity and censoring of landscape phage libraries. Protein Eng Des Sel 22: 9-18, 2009.

54. Brammer LA, Bolduc B, Kass JL, Felice KM, Noren CJ and Hall MF: A target-unrelated peptide in an M13 phage display library traced to an advantageous mutation in the gene II ribosome-binding site. Anal Biochem 373: 88-98, 2008

55. Menendez A and Scott JK: The nature of target-unrelated peptides recovered in the screening of phage-displayed random peptide libraries with antibodies. Anal Biochem 336: 145-157, 2005.

56. Sasso E, D'Avino C, Passariello M, D'Alise AM, Siciliano D, Esposito ML, Froechlich G, Cortese R, Scarselli E, Zambrano N, et al: Massive parallel screening of phage libraries for the generation of repertoires of human immunomodulatory monoclonal antibodies. MAbs 11: 1-13, 2018.

57. Harper J, Mao S, Strout P and Kamal A: Selecting an optimal antibody for antibody-drug conjugate therapy: Internalization and intracellular localization. Methods Mol Biol 1045: 41-49, 2013.0

This work is licensed under a Creative Commons

Attribution-NonCommercial-NoDerivatives 4.0 International (CC BY-NC-ND 4.0) License. 